\title{
Hubris-Humility Effect and Domain-Masculine Intelligence Type in Czech Republic
}

\author{
Adrian Furnham, Josephine Storek \\ University College London, London, UK
}

\begin{abstract}
Czech adults completed a self-assessed intelligence measure that yielded a score on domainmasculine intelligence (DMIQ), a composite of mathematical/logical and spatial intelligences. They also completed a sex role inventory. The sex of the participants but not their sex role was related to DMIQ. There was a positive relationship between masculinity and DMIQ, but only for males. Cultural issues in self assessed intelligence and limitations of this study are considered.

Key words: self assessed intelligence, domain masculine intelligence, Czech Republic
\end{abstract}

\section{Introduction}

This study is primarily concerned with selfestimated intelligence (SEI) (Freund \& Kasten, 2012; Kaufman, 2012). Over thirty studies that used the 'multiple' self-estimated intelligences model (Furnham, 2000) have found that gender differences were strongest on the mathemati$\mathrm{cal} /$ logical and spatial intelligences, followed by overall ('g') and verbal intelligences, with males significantly overestimating, and females significantly underestimating, their abilities. This consistent gender difference has been referred to as the Hubris-Humility Effect (HHE).

A meta-analytical study, investigating the magnitude of gender differences in mathematical/logical, spatial, overall and verbal self-assessed intelligences (Szymanowicz \& Furnham, 2011), found that the biggest weighted mean

Correspondence concering this article should be addressed to Adrian Furnham D.Phil (Oxon), D.Sc (Lond), D.Litt (Natal), FBPS FAcSS, Professor of Psychology, University College London, London, UK, E-mail: a.furnham@ucl.ac.uk

Received January 15, 2016 effect sizes were for mathematical/logical, $(d=$ $.44)$, followed by spatial $(d=.43)$, overall $(d=.37)$ and verbal $(d=.07)$ intelligence, with males providing higher estimates in all but verbal intelligence. Furnham (2000) proposed that people view intelligence as 'male-normative', since mathematical/logical and spatial intelligences are areas where males are believed to excel. Storek and Furnham (2012, 2013ab, 2014, 2016) introduced the concept of 'domain-masculine intelligence' (DMIQ), a composite of mathemati$\mathrm{cal} /$ logical and spatial intelligences.

This study aims to confirm the existence of the Hubris-Humility Effect on the Domain-Masculine Intelligence Type with participants from Czech Republic. The effect sizes for the Czech sample are expected to be smaller than those in various British populations. This idea was based on a previous study that examined selfestimated intelligence among Slovaks and the cultural similarity between Czechs and Slovaks (Furnham, Rakow, Sarmany-Schuller, \& De Fruyt, 1999). Thus, it was hypothesized that HHE will be observed on DMIQ (H1) but that the observed effect size will be smaller than in previous studies $(\mathrm{H} 2)$.

Gender stereotypes are thought to play role in HHE (Petrides et al., 2004) and were shown to 
be most pronounced in areas that are associated with 'masculine' and 'feminine' characteristics, such as math/sciences and arts (Brown \& Josephs, 1999). These stereotypes were also exposed to negatively impact performance and ability perception in women on tasks that are perceived as masculine, such as math (Rudman \& Phelan, 2010). Accordingly, gender is expected to influence the relationship between masculinity and DMIQ (H3) and between femininity and the intelligence type (H4). Given that Czech Republic is not a high masculinity culture it seems probable for gender to account for most variance in the intelligence type. Consequently, gender is expected to be the best predictor of DMIQ over and above masculinity and femininity(H5).

\section{Method}

\section{Participants}

There were 85 females (73\%) and 31 males. Their age raged from 17 to $50(M=30.83, S D=$ 8.19 ) years. $78 \%$ of the participants had achieved A-level or similar level of education, $4 \%$ reached non-university level of education and $17 \%$ had earned BA/BSc level of education. A wide range of professions was observed, from student teachers $(30 \%)$, to nursing students $(27 \%)$, to civil servant $(10 \%)$ to liberal professions $(16 \%)$, police officers $(6 \%)$, managers $(3 \%)$, managing directors $(2 \%)$, entrepreneurs $(2 \%)$, secretaries $(2 \%)$, and chefs $(2 \%)$.

\section{Measures}

1. Self-estimated Intelligence (SEI) (Furnham \& Gasson, 1998)

The measure consists of a normal IQ score distribution $(M=100, S D=15)$ with descriptive labels and a normal distribution IQ curve figure. The average score is 100 , a score of 55 is labelled 'mild retardation', a score of 75 a 'bor- derline retardation', a score of 85 'low average', score of 115 'high average', score of 130 'superior', and that of 145 'gifted'. Thereafter, a table with the ten labelled and briefly described intelligence types and the overall- estimated IQ score was provided, e.g. 'Verbal/Linguistic Intelligence: the ability to speak fluently along with understanding of grammar (syntax) and meaning (semantics)'. Alpha for Domain-Masculine Intelligence Type was .62 and the inter-item correlation $r=.45$.

2. Gender Identity: Bem Sex Role Inventory (BSRI) (Bem, 1981)

This non-timed 60-item measure is designed to measure the orthogonal constructs of masculinity and femininity. The scale has been shown to have satisfactory internal reliability and homogeneity, with alphas for masculinity .86 and femininity .74 (Francis \& Wilcox, 1998). The alphas for masculinity and femininity in this study were, .86 and .77 , respectively.

\section{Procedure}

All participants were living in Prague and Czech was their mother tongue. All documents were translated into Czech and back-translated to English by the main researcher and the local research assistant. The main researcher was fluent in Czech and the local research assistant was a native Czech speaker, fluent in English. No discrepancies were found. Pilot work indicated no difficulties.

\section{Results}

Hubris-Humility Effect and the Domain-Masculine Intelligence Type

An independent t-test, $t(114)=-3.05, p<.01$, two-tailed, confirmed significant differences between males $(M=107.66, S D=10.61)$ and females $(M=100.75, S D=10.89)$. The magnitude of the differences in the means (mean dif- 
ference $=-6.91,95 \% \mathrm{CI}:-11.41$ to -2.42$)$ was medium $\left(\eta^{2}=.08\right.$; Hodge's Adjustment $\left.d=.64\right)$. Hypothesis 1 was confirmed. The effect size was found in the Czech Republic sample $\left(\eta^{2}=.08\right.$; Hodge's Adjustment $\left.d=.64\right)$, confirming hypothesis 2 .

\section{Impact of Gender, Masculinity and Feminin- ity on the DMIQ}

Masculinity was collapsed into categorical variable, with Group 1 containing subjects with lowest masculinity scores, Group 2 subjects with average masculinity and Group 3 subjects with highest masculinity scores. Identical analysis was carried out with Femininity. Results are presented in Table 1.

Two two-way between-groups analyses of variance were conducted to explore whether gender moderates the relationship between masculinity and the intelligence type as well as femininity. Results are presented in Table 2.

Neither the main effect for masculinity or femininity, or the interaction was significant. The main effect for gender was significant. A Bonferroni test revealed no significant differ-

Table 1 Overview of masculinity and femininity banded

\begin{tabular}{lcc}
\hline & Masculinity & $n$ \\
\hline Group 1 & $<=4$ & 39 \\
Group 2 & 5 & 39 \\
Group 3 & $6+$ & 38 \\
\hline & Femininity & $\mathrm{n}$ \\
\hline Group 1 & $<=5$ & 39 \\
Group 2 & $5-6$ & 38 \\
Group 3 & $6+$ & 38 \\
\hline
\end{tabular}

Note. Computed using Visual Bander technique (SPPS 13.0)

Table 2 Two 2-way ANOVAs (Masculinity and gender and femininity and gender) on DMIQ

\begin{tabular}{|c|c|c|c|c|c|c|c|}
\hline \multirow[t]{2}{*}{ Variable } & \multirow[t]{2}{*}{$\begin{array}{l}\text { Tot ' } g \text { ' } \\
\text { score }\end{array}$} & \multicolumn{3}{|c|}{$\begin{array}{c}\text { Mean Score } \\
(S D)\end{array}$} & \multicolumn{3}{|c|}{$F$-score } \\
\hline & & Total & Males & Females & $\mathrm{M} / \mathrm{F}$ & Gender & $M \times G$ \\
\hline \multirow[t]{5}{*}{ Masculinity } & G1 (L) & $\begin{array}{r}98.87 \\
(952)\end{array}$ & $\begin{array}{l}105.00 \\
(1061)\end{array}$ & $\begin{array}{l}98.17 \\
(9) 29)\end{array}$ & .51 & $5.09 *$ & .61 \\
\hline & $\mathrm{G} 2(\mathrm{M})$ & 104.14 & 105.91 & 103.45 & & & \\
\hline & & $(12.28)$ & $(10.20)$ & $(13.11)$ & & & \\
\hline & G3 (H) & 104.83 & 109.53 & 101.41 & & & \\
\hline & & (10.94) & (11.19) & $(9.62)$ & & & \\
\hline \multirow[t]{6}{*}{ Femininity } & G1 (L) & 103.03 & 106.43 & 101.12 & .38 & $9.08 * *$ & .31 \\
\hline & & $(10.41)$ & $(9.18)$ & $(10.74)$ & & & \\
\hline & G2 (M) & 100.97 & 106.50 & 99.00 & & & \\
\hline & & (12.91) & (14.63) & (11.91) & & & \\
\hline & G3 (H) & 103.58 & 112.08 & 101.98 & & & \\
\hline & & (10.32) & $(6.21)$ & $(10.21)$ & & & \\
\hline
\end{tabular}

Note. DMIQ1 $=$ Domain-Masculine Intelligence Type

$* p<.05, * * p<.01, * * * p<.001$ (2-tailed) 
ences in mean scores between three groups. Hypothesis 3 was partially confirmed. The main effect for gender was significant. Bonferroni tests indicated the mean scores of the three groups did not significantly differ. Hypothesis 4 was partially confirmed.

Gender and Gender Identity as Predictors of the Domain-Masculine Intelligence Type

The relationship between gender, gender identity variables and DMIQ was explored. The results of the correlational and partial correlational analyses are presented in Table 3. Gender correlated positively with DMIQ, with males providing higher scores than females. Mascu- linity, but not femininity, correlated with DMIQ, which supports the assertion that DMIQ is perceived as male-normative and as such evokes masculinity gender-role stereotypical associations (Furnham, 2001).

The data was split per gender and the correlations recomputed. Results are presented in Table 4. The only significant relationship was observed in the male subsample, between DMIQ and masculinity with highly masculine males providing higher DMIQ estimates.

DMIQ was regressed onto gender and gender identity to ascertain which variable is the best predictor of the intelligence type. Results are presented in Table 5. Preliminary analyses were conducted to ensure no violation of the

Table 3 Correlations and partial correlations, means and standard deviations between DMIQ, gender and gender identity and age

\begin{tabular}{|c|c|c|c|c|c|c|}
\hline & $\begin{array}{l}X \\
(S D)\end{array}$ & $\begin{array}{c}\text { DMIQ } \\
102.59 \\
(11.20)\end{array}$ & $\begin{array}{l}\mathrm{G} \\
1.27 \\
(.44)\end{array}$ & $\begin{array}{l}\mathrm{M} \\
4.45 \\
(.76)\end{array}$ & $\begin{array}{l}\mathrm{F} \\
4.99 \\
(.60)\end{array}$ & $\begin{array}{l}\mathrm{A} \\
30.83 \\
(8.19)\end{array}$ \\
\hline Domain-masculine IQ T1 & (DMIQ) & & & & & \\
\hline Gender & (G) & $.27 * *$ & & & & \\
\hline Masculinity & (M) & $.28 * *$ & $.34 * * *$ & & & \\
\hline Femininity & (F) & -.05 & $-.20 *$ & .15 & & \\
\hline Age & (A) & $.21 *$ & .10 & .13 & .03 & \\
\hline \multicolumn{7}{|l|}{ Controlled for Age } \\
\hline Domain-masculine IQ T1 & (DMIQ1) & & & & & \\
\hline Gender & $(\mathrm{G})$ & $.26 * *$ & & & & \\
\hline Masculinity & (M) & $.26 * *$ & $.33 * * *$ & & & \\
\hline Femininity & (F) & -.06 & $-.20 *$ & .14 & & \\
\hline
\end{tabular}

Table 4 Correlations, means and standard deviations between DMIQ, gender identity and age-per gender

\begin{tabular}{lll}
\hline Variables & DMIQ Males & DMIQ Females \\
$M$ & 107.66 & 100.75 \\
$(S D)$ & $(10.61)$ & $(10.89)$ \\
\hline Masculinity & $.38 *$ & .14 \\
Femininity & .05 & -.02 \\
Age & .22 & .18 \\
\hline$* p<.05, * * p<.01, * * * p<.001$ (2-tailed). $N=$ between 30 and 85.
\end{tabular}


Table 5 Hierarchical regression of gender and gender identity variables onto DMIQ

\begin{tabular}{|c|c|c|c|}
\hline \multirow{2}{*}{$\begin{array}{l}\text { Regression } \\
\text { Models }\end{array}$} & \multicolumn{3}{|c|}{ Domain-Masculine IO } \\
\hline & Standardised $\beta$ & $t$ & $r_{\text {part }}$ \\
\hline \multicolumn{4}{|l|}{ Step 1: } \\
\hline Gender & .27 & $3.03 * *$ & .27 \\
\hline Regression Model $^{1}$ & & $\mathrm{~F}(1,113)=9.20^{* *}$ & \\
\hline $\mathrm{R}^{2}$ & & .08 & \\
\hline $\mathrm{R}^{2}$ Change & & .08 & \\
\hline Adj. $R^{2}$ & & .07 & \\
\hline $\mathrm{f}^{2}$ & & .09 & \\
\hline \multicolumn{4}{|l|}{ Step 2: } \\
\hline Gender & .19 & 1.94 & .17 \\
\hline Masculinity & .22 & $2.26^{*}$ & .20 \\
\hline Femininity & -.04 & -.45 & -.04 \\
\hline Regression Model $^{2}$ & & $\mathrm{~F}(3,111)=4.86^{* *}$ & \\
\hline $\mathrm{R}^{2}$ & & .12 & \\
\hline $\mathrm{R}^{2}$ Change & & .04 & \\
\hline Adj. $R^{2}$ & & .09 & \\
\hline $\mathrm{f}^{2}$ & & .14 & \\
\hline
\end{tabular}

Note. Significant values are in bold

$* p<.05 ; * * p<.01 ; * * * p<.001$

assumptions of normality, linearity, multicollinearity and homoscedasticity.

Gender was entered in Step 1, explaining 7\% of the variance in DMIQ. When the gender identity variables, i.e. masculinity and femininity, were added at Step 2, gender failed to reach significance. The overall regression was significant with the overall model explaining $12 \%$ of total variance in the intelligence type. Contrary to the hypothesis, gender was not a significant predictor but masculinity was the best predictor of DMIQ.

\section{Discussion}

This study set out to confirm the existence of HHE on DMIQ in Czech sample. Based on results of SEI study with a Slovakian sample (Furnham et al., 1999), a culture historically and socio-politically similar to Czech Republic that did not replicate the existence of HHE, the effect sizes were expected to be small. The results confirmed the existence of HHE on DMIQ $\left(\eta^{2}=\right.$ $.08, d=.64)$. However, the observed medium effect size was small compared to that for recent British data (Storek \& Furnham, 2012). Hence, the results provided support for the existence of cultural disparity in gender differences in HHE and DMIQ between Czech Republic and United Kingdom as well as affirmed the uniqueness of Czech culture from the Slovakian culture.

Hypotheses 3 and 4 were concerned with gender's influence on the relationship between masculinity, femininity and DMIQ in order to provide further evidence for the finding that gender stereotypes are most pronounced in areas that are associated with 'masculinity' and 
'femininity'. Moreover, gender stereotypes have a negative impact on perceived ability as well as performance in women, especially on 'masculine' tasks (Rudman \& Phelan, 2010) and are assumed to play a role in HHE (Petrides et al., 2004). The results revealed significant gender effects for both masculinity and femininity but no significant interaction effect. Males provided higher DMIQ estimates on all three masculinity groups and surprisingly also on all three femininity groups. This finding suggests that Czech men either do not differentiate between the gender identity variables or view both as equally important. Equally, the results confirm Hofstede's claim (2003) that Czech Republic is an average masculine society as well as affirms the existence of 'hubris' among Czech males.

The correlational analysis validated the assertion that SEI, and in particular mathematical/ logical and spatial intelligences, are perceived as male-normative (Furnham, 2001), as demonstrated through DMIQ's relationship with masculinity but not femininity. These results were confirmed when the sample was split per gender and the correlations recalculated, revealing a medium positive relationship between masculinity and DMIQ, but only for males. This implies that Czech men associate DMIQ with masculinity.

Since previous studies that used gender identity variables found conflicting results, and given that Czech Republic is an average masculinity country, gender was predicted as the best predictor of DMIQ. The results refuted this claim and confirmed masculinity as the best and only predictor, accounting for $4 \%$ of the variance in DMIQ. Overall, the findings confirm the existing literature and previous studies in the area within Czech Republic sample.

\section{References}

Ackerman, P., \& Wolman, S. (2007). Determinants and validity of self-estimates of ability and self-con- cept measures. Journal of Experimental Psychology: Applied, 13, 59-78.

Beier, M. E., \& Ackerman, P. L. (2003). Determinants of health knowledge: An investigation of age, gender, abilities, personality, and interests. Journal of Personality and Social Psychology, 84, 439-448.

Bem, S. L. (1981). Bem Sex Role Inventory: Professional manual. Palo Alto, CA: Consulting Psychologists Press.

Brown, R. P., \& Josephs, R. A. (1999). A burden of proof: Stereotype relevance and gender differences in math performance. Journal of Personality and Social Psychology, 76, 246-257.

Francis, L. J., \& Wilcox, C. (1998). The relationship between Eysenck's personality dimensions and Bem's masculinity and femininity scales revisited. Personality and Individual Differences, 25, 683-687.

Freund, P., \& Kasten, N. (2012). How smart do you think you are? A meta-analysis on the validity of self-estimates of cognitive ability. Psychological Bulletin, 138(2), 296-321.

Furnham, A. (2000). Parents' estimates of their own and their children's multiple intelligences. British Journal of Developmental Psychology, 18, 583594.

Furnham, A. (2001). Self-estimates of intelligence: Culture and gender difference in self and other estimates of both general $(g)$ and multiple intelligences. Personality and Individual Differences, 31, 13811405.

Furnham, A., Rakow, T., Sarmany-Schuller, I., \& De Fruyt, F. (1999). European differences in self-perceived multiple intelligences. European Psychologist, 4, 131-138.

Gardner, H. (1983). Frames of mind: The Theory of Multiple Intelligences. NY: Basic Books.

Hofstede, G. (2003). Culture's consequences, comparing values, behaviours, institutions, and organizations across nations. ( $2^{\text {nd }}$ Ed.) Thousand Oaks, CA: Sage Publications.

Kaufman, J. (2012). Self estimates of general, crystallized, and fluid intelligences in an ethnically diverse population. Learning and Individual Differences, 22(1), 118-122.

Petrides, K. V., Furnham, A., \& Martin, G. N. (2004). Estimates of emotional and psychometric intelligence: Evidence for gender-based stereotypes. Journal of Social Psychology, 144, 149-162.

Rudman, L. A., \& Phelan, J. E. (2010). The effect of priming gender roles on women's implicit gender beliefs and career aspirations. Social Psychology, 41, 192-202.

Storek, J., \& Furnham, A. (2012). Gender and gender role differences in Domain-Masculine Intelligence and beliefs about intelligence: A study with Mensa 
UK members. Personality and Individual Differences, 53, 890-895.

Storek, A., \& Furnham, A. (2013a). Gender, 'g', and fixed versus growth intelligence mindsets as predictors of self-estimated Domain Masculine Intelligence (DMIQ). Learning and Individual Differences, 25, 93-98.

Storek, J., \& Furnham, A. (2013b). Gender, g, gender identity concepts and self-constructs as predictors of the self-estimated IQ. Journal of Genetic Psychology, 174,_664-676

Storek, J., \& Furnham, A. (2014). Gender and task confidence as predictors of the Domain-Masculine
Intelligence type (DMIQ). Personality and Individual Differences, 69, 43-48

Storek, J., \& Furnham, A. (2016). The role of gender, task success probability estimation and score as predictors of the Domain-Masculine Intelligence type (DMIQ). Learning and Individual Differences, 50, 23-29.

Szymanowicz, A., \& Furnham, A. (2011). Gender differences in self-estimates of general, mathematical, spatial, and verbal intelligence: Four meta-analyses. Learning and Individual Differences, 21, 493504 . 